\title{
Scientific Exploration of Ingredients of katak Khadiradi Kashyayamfor Their Anti Diabetic Property
}

\author{
${ }^{1}$ Dr Kolhe NS, ${ }^{2}$ Dr Bapat VA \\ ${ }^{1}$ Associate Professor department of Rog evam vikriti Vigyan SKAM College Chilapur,Varanasi. \\ ${ }^{2}$ Panchakarma Vaidya PG Department of Panchakarma National Institute of Ayurveda Jaipur.
}

\begin{abstract}
:-
Background:-A huge number of drugs are prescribed by Ayurvedic physicians to the patients of diabeteslike diseases and number of preparation are traditionally used by different school of practitioners, since thousands of years. Among them Katak Khadiradi Kashayamhas been advocated in Sahasra Yogam(A popular book on Kerliya tradition of Ayurvedic treatment). Andis being practiced in Southern part of India,since two hundred years to treat Diabetes Mellitus. Though principally its mode of action is well established as per Ayurvedic parameters, it is a need of time to establish this on the basis of modern biochemical and pharmacological parameters.

Methods:-we searched Pubmed and scholarly articles with the help of google search engine to see that is there any kind of alkaloid present in any drug of this combination which shows antidiabetic or hypoglycemic effect.For this each drug of this combination is studied separately on the basis of previous researches especially animal experiments and data is gathered.

Results:- Extract of almost each drug shows anti-hyperglycemic effect along with rejunuvative and antioxidant properties in experimental or animal studies.

Conclusion:-Hence, Katak Khadiradi Kashayam has an effect on protecting $\beta$-cells and smoothing out fluctuation in glucose levels. shows antidiabetic effect along with antioxidant property which can be very helpful for diabetes Mellitus.
\end{abstract}

Key words: - Ayurveda ,Katak Khadiradi Kashayam ,Diabetic Mellitus.

\section{INTRODUCTION}

Ayurveda has exercised its sovereignty by virtue of its time-proven principles, since the dawn of civilization of mankind .Different principles have been framed on the basis of a series of experimental and exploration in various fields like treatment modality, diagnosis, drug identification and mode of action of drug etc. Acharyas have adopted the contemporary prevailing knowledge into the compendium, in order to make it a sustainable for the time .Many technological advances which are rationally justified by current parametric assessment.

Diabetes mellitus (DM) comprises a group of common metabolic disorders that share the phenotype of hyperglycemia. Several distinct types of DM exist and are caused by acomplex interaction of genetics, environmental factors, and life-style choices. Depending on the etiology of the DM, factors contributing to hyperglycemia may include reduced insulin secretion, decreased glucose utilization, and increased glucose production. The metabolic dysregulation associated with DM causes secondary pathophysiologic changes in multiple organ systems that impose a tremendous burden on the individual with diabetes and on the health 
${ }^{1}$ Dr Kolhe NS , International Journal of Ayurvedic\& Herbal Medicine 7(4) July.-Aug. 2017 (2779-2789)

care system. In the United States, DM is the leading cause of end-stage renal disease (ESRD), nontraumatic lower extremity amputations, and adult blindness. With an increasing incidence worldwide, DM will be a leading cause of morbidity and mortality for the foreseeable future ${ }^{i}$. Diabetes mellitus is a chronic metabolic disease which now afflicts $3 \%$ of the world population. Diabetes mellitus is classified into two types (type 1 and 2) based on individual etiologies. Around $95 \%$ of diabetic patients are diagnosed with type 2 diabetes ${ }^{\mathrm{ii}}$. A major feature of type 2 diabetes is insulin resistance and/or insulin deficiency which can cause hyperglycemia $^{\text {iii }}$. The pathogenesis of diabetes mellitus and the possibility of its management by existing therapeutic agents without any side effects have stimulated great interest in recent years

Diabetes mellitus is a syndrome characterized by chronic hyperglycemia and disturbances of carbohydrate, fat and protein metabolism associated with absolute or relative deficiency in insulin secretion or insulin action (Jayakar and Suresh, 2003). During hyper glycemia

excessive production of free radicals is believed to be involved in many diabetic complications including diabetic neuropathy in diabetes mellitus (Sima and Sugimoto,1999). Besides hyperglycemia, severa other factors including dyslipidaemia or hyperlipidemia are involved in the development of micro and macro vascular complications of diabetes which are the major causes of morbidity and death (Bennet and Joslin's, 1998). Diabetes mellitus is also associated with hyperlipidaemia with profound alteration in the concentration and composition of lipid (Odetola et al, 2006). Changes in the concentration of lipid with diabetescontribute to the development of vascular disease ${ }^{\text {iv }}$.

For treatment we have to establish target level of glycemic control - Because the complications of DM are related to glycemic control, normoglycemia or near normoglycemia is the desired, but often elusive, goal for most patients. However, normalization of the plasma glucose for long periods of time is extremely difficult, as demonstrated by the DCCT. Regardless of the level of hyperglycemia, improvement in glycemic control will lower the risk of diabetes complications. The target for glycemic control (as reflected by the A1C) must be individualized, and the goals of therapy should be developed in consultation with the patient after considering a number of medical, social, and lifestyle issues. Some important factors to consider include the patient's age, ability to understand and implement a complex treatment regimen, presence and severity of complications of diabetes, ability to recognize hypoglycemic symptoms, presence of other medical conditions or treatments that might alter the response to therapy, lifestyle and occupation (e.g., possible consequences of experiencing hypoglycemia on the job), and level of support available from family and friends $\mathrm{v}$.

Different types of oral hypoglycemic agents are available along with insulin for the treatment of diabetes mellitus but their long-term use produces undesirable side effects such as skin rashes, transient leucopenia, thrombocytopenia, severe hypoglycemia, and increase chances of cardiovascular death of unknown mechanism $^{\mathrm{vi}}$.

The traditional medicines demonstrated a bright future in therapy of diabetes and to understand the importance of traditional herbs, traditionally many medicinal plants have been in use to manage diabetes like clinical conditions and some medicinal plants have been reported to be useful in diabetes worldwide and have been used with limited or no scientific justification of their anti-diabetic and anti-hyperglycemic effect. A huge number of drugs have been described in context to diabetes-like diseases in Ayurvedic classic, and number of preparation are practically used by different school of practitioners, since thousands of years.

Among them

1. Kataka-Strychnos potatorum

2. Khadira-Acacia catechu

3. Dhatri-Amla - Phyllathus Embelica/ Emblica officinalis

4. Vairi-Salacia reticulata 
${ }^{1}$ Dr Kolhe NS , International Journal of Ayurvedic\& Herbal Medicine 7(4) July.-Aug. 2017 (2779-2789)

5. Darvi-Berberis aristata

6. Samanga-Cassia mimosoides / Biophytum sensitivum Linn.

7. Vidula - Barringtonia acutangula

8. Rajani-Turmeric-Curcuma longa

9. Patha-Cyclea peltata/Cissampelos parerieta

10. Chootabija-Mango seed-Mangifera indica

11. Abhaya-Terminalia chebula

12. Abda-Cyperus rotundus

has been advocated in "Sahasra Yogam" A Popular Book on Keraliya tradition of Ayurvedic treatment and being practiced in Southern part of India since two hundred years in Diabetes Mellitus.

\section{Methadology}

Each ingredient of this formulation is studied separately for its possible action on hyperglycemia and antidiabetic property with the help of google search engine, pubmed, scholary articles. Experimental and animal studies are primarily taken in consideration and listed accordingly.

Antihyperglycemic Activity of Strychnos potatorum Seed and Leaf Methanolic Extracts in AlloxanInduced Diabetic Rats.

An experimental study was carried out by T. Pandu Raju, et al for the antidiabeticactivity of different solvents extracts of seeds and leaves of Strychnos potatorum. The study used oral administration of methanolic extracts of seeds and leaves of Strychnos potatorum @ 200 and $400 \mathrm{mg} / \mathrm{kg}$ b.w. at every 3 hour interval to alloxan induced diabetic rats and the findings showed reduced blood glucose levels by $24.23 \%$, $25.67 \%, 16.47 \%$ and $17.88 \%$ in different groups ${ }^{\mathrm{vii}}$.

Biochemical study on the hypoglycaemic effects of extract and fraction of Acacia catechu willd in alloxan-induced Diabetic Rats.

An experimental study was carried out by Edwin Jarald et al. on the effective extract and fraction of $A$. catechu were subjected to anti-diabetic study in alloxan-induced diabetic rats at two dose levels, 200 and $400 \mathrm{mg} / \mathrm{kg}$, respectively. Biochemical parameters, including glucose, urea, creatinine, serum cholesterol, serum triglyceride, high density lipoprotein (HDL), low density lipoprotein (LDL), haemoglobin and glycosylated haemoglobin were also assessed. The ethanolic extract of $A$. catech $u$ and the water insoluble fraction of ethanolic extract exhibited significant anti-hyperglycaemic activity and produced dosedependent hypoglycemia in fasted normal rats. Treatment of diabetic rats with ethanolic extract and waterinsoluble fraction of this plant restored the elevated biochemical parameters significantly $(\mathrm{p}<0.05)$ to the normal level. Comparatively, the water insoluble fraction of ethanolic extract was more effective than the ethanolic extract and the activity was comparable to that of the standard, glibenclamide $(5 \mathrm{mg} / \mathrm{kg})^{\text {viii }}$.

Antidiabetic and Antihyperlipidemic Properties of Phyllanthus emblica Linn. (Euphorbiaceae) on Streptozotocin Induced Diabetic Rats

An experimental study was carried out by Mani Krishnaveni et al. on the Ethanol extracts of Phyllanthus emblica fruits administered orally at doses of $200 \mathrm{mg} / \mathrm{kg}$ body weight for 45 days resulted in a significant reduction in blood glucose and a significant increase in plasma insulin in diabetic rats ${ }^{\mathrm{ix}}$.

Evaluation of immunomodulatory potential of Emblica officinalis fruit pulp extract in mice.

An experimental study was carried out by Suja R. S. et al on the Aqueous extract of dried Emblica officinalis Gaertn. (Amla) fruit pulp powder was evaluated for immunomodulatory effect on male Swiss Albino mice. The mice were divided into three groups. The first group received vehicle alone to serve as control. The second and third groups received the extract orally at 100 and $200 \mathrm{mg} / \mathrm{kg}$ body weight dose levels respectively per day for a period of 19 days. There was significant dose dependent increase in 
${ }^{1}$ Dr Kolhe NS , International Journal of Ayurvedic\& Herbal Medicine 7(4) July.-Aug. 2017 (2779-2789)

haemagglutination antibody titre, sheep red blood cells induced delayed type of hypersensitivity reaction, macrophage migration index, respiratory burst activity of the peritoneal macrophages, total leukocyte count, percentage lymphocyte distribution, serum globulin and relative lymphoid organ weight in Emblica treated mice indicating its ability to stimulate humoral as well as cell mediated immunity along with macrophage phagocyte $^{\mathrm{x}}$.

\section{Salacia Extract Improves Postprandial Glucose and Insulin Response: A Randomized Double-Blind,} Placebo Controlled, Crossover Study in Healthy Volunteers ${ }^{x i}$

A Clinical study was carried out by Jeykodi et al It is a placebo controlled randomized crossover design study. Subjects were given oral sucrose solution along with capsules and plasma glucose and insulin responses were analyzed.Subjects treated with SCE have reduced blood glucose and insulin. Elevation of insulin levels following sucrose loading was also significantly inhibited by SCE compared with placebo; the inhibition was significant at 30 and 60 minutes after administration of 300 and $500 \mathrm{mg}$ SCE.SCE markedly decreased digestion and absorption of sucrose by its inhibitory action on sucrase and then reduced increases in blood glucose and insulin without serious adverse effect. Therefore, SCE might afford a safe and effective supplementary means for controlling metabolic health and healthy blood glucose and insulin levels.

\section{Hypoglycemic Activity of Casearia esculenta Roxb.in Normal and Diabetic Albino Rats.}

An experimental study was carried out by Balasubramanian Arula et al. on the ethanolic extract of $C$. esculenta $(250 \mathrm{mg} / \mathrm{kg})$ reduced the blood glucose of normal rat from 85.50 ? $-/+1.22$ to 64.67 ? $-/+3.27 \mathrm{mg} / \mathrm{dl}$, $3 \mathrm{~h}$ after oral administration of the extract $(\mathrm{P}<0.05)$. It also significantly lowered blood glucose level in alloxan induced diabetic rat from 331.67? $-/+4.90$ to 130.33 ? $-/+6.53 \mathrm{mg} / \mathrm{dl}, 3 \mathrm{~h}$ after oral administration of the extract $(\mathrm{P}<0.05)^{\mathrm{xii}}$.

\section{Antihyperglycemic activity of root of Berberis aristata D.C. in alloxan-induced diabetic rats}

An experimental study was carried out by Bhupesh Chander Semwal et al. on the different extracts of root of $B$. aristata were also tested for glucose tolerance test normal fasted rats. The ethanol extract of root of $B$. aristata 71.42 and $100 \mathrm{mg} / \mathrm{kg}$ body weight showed a significant $(P<0.01)$ reduction of serum glucose level in alloxaninduced diabetic rats at 15 th day as compared to diabetic control group ${ }^{\text {xiii }}$.

\section{Effect of Biophytum sensitivum on streptozotocin and nicotinamide-induced diabetic rats.}

An experimental study was carried out by Ananda et al on male albino rats at Department of experimental Medicines, Annamalai University. Body weight, plasma insulin and $\mathrm{Hb}$ decreased, urine sugar and $\mathrm{HbA}$ cc increased significantly in diabetic control rats, and these values were reversed by treatment with BSEt (200 $\mathrm{mg} / \mathrm{kg}$ b.w.). A significant elevation in plasma insulin was also observed in normal rats treated with BSEt as compared with normal control rats. Normal rats treated with BSEt also showed a significant elevation in the activities of hexokinase and level of glycogen and non-significant decrease in the activities of glucose-6phosphatase and fructose-1,6-bisphophatase were observed as compared with normal control rats. Administration of BSEt and glibenclamide significantly reduced the activities of gluconeogenic enzymes in diabetic rats. The levels of plasma insulin were found to increase significantly in diabetic rats treated with BSEt, which may be a consequence of the significant reduction in the level of gluconeogenic enzymes. The reduction in the activities of gluconeogenic enzymes can result in the decreased concentration of glucose in blood $^{\text {xiv }}$.

\section{Evaluation of hypoglycemic activity of Barringtonia Acutangula Fruit extracts in streptozotocin induced Hyperglycemic wistar rats}

An experimental study carried out by Khatib et al to evaluate hypoglycemic activity of BA fruit extracts in euglycemic and streptozotocin (STZ) induced hyperglycemic Wistar rats of either sex.The acute administration of aqueous extract at $400 \mathrm{mg} / \mathrm{kg}$ significantly improved oral glucose tolerance in glucose 
${ }^{1}$ Dr Kolhe NS , International Journal of Ayurvedic\& Herbal Medicine 7(4) July.-Aug. 2017 (2779-2789)

loaded normal rats indicating its antihyperglycemic activity, acute and chronic study in STZ induced hyperglycemic rats also showed significant antihyperglycemic action. Whereas no such effect were seen with methanol and chloroform extracts. The histological studies demonstrated severe changes in the pancreas of STZ induced hyperglycemic rats [18,19], whereas BA fruit aqueous extract treatment shows significant recovery when compared with untreated hyperglycemic rats, this could signify the regeneration of beta cells of islets of Langherhans ${ }^{\mathrm{xv}}$.

\section{Curcuminoids and Sesquiterpenoids in Turmeric (Curcuma longa L.) Suppress an Increase in Blood} Glucose Level in Type 2 Diabetic KK-Ay Mice.

An experimental study was carried out by Tozo Nishiyama et al in this study, theyinvestigated the effects of three turmeric extracts on blood glucose levels in type 2 diabetic KK-Ay mice ( 6 weeks old, $n=5 /$ group). These turmeric extracts were obtained by ethanol extraction (E-ext) to yield both curcuminoids and sesquiterpenoids, hexane extraction (H-ext) to yield sesquiterpenoids, and ethanol extraction from hexane-extraction residue (HE-ext) to yield curcuminoids. The control group was fed a basal diet, while the other groups were fed a diet containing 0.1 or $0.5 \mathrm{~g}$ of H-ext or HE-ext/100 g of diet or 0.2 or $1.0 \mathrm{~g}$ of Eext/100 g of diet for 4 weeks. Although blood glucose levels in the control group significantly increased $(P<$ 0.01 ) after 4 weeks, feeding of 0.2 or $1.0 \mathrm{~g}$ of E-ext, $0.5 \mathrm{~g}$ of H-ext, and $0.5 \mathrm{~g}$ of HE-ext/100 $\mathrm{g}$ of diet suppressed the significant increase in blood glucose levels. Furthermore, E-ext stimulated human adipocyte differentiation, and these turmeric extracts had human peroxisome proliferator-activated receptor- $\gamma$ (PPAR$\gamma$ ) ligand-binding activity in a GAL4-PPAR- $\gamma$ chimera assay. Also, curcumin, demethoxycurcumin, bisdemethoxycurcumin, and ar-turmerone had PPAR- $\gamma$ ligand-binding activity. These results indicate that both curcuminoids and sesquiterpenoids in turmeric exhibit hypoglycemic effects via PPAR- $\gamma$ activation as one of the mechanisms, and suggest that E-ext including curcuminoids and sesquiterpenoids has the additive or synergistic effects of both components ${ }^{\mathrm{xvi}}$.

\section{Effect of Curcuma Longa freeze dried rhizome powder with milk in stz induced diabetic rats}

An experimental study carried out by Rai PK et al for determination of anti-diabetic, antilipedemic and hepatoprotective attributes in severly diabetic rats. experimental trial was carried out by evaluating fasting blood glucose, glucose tolerance test, Lipid profile and serum enzymes. The maximum fall observedduring FBG and GTT studies was 17.7 and $27.9 \%$ respectivelywith the dose of $200 \mathrm{mgkg}$-1of C. longain normal rats. Thehypoglycemic activity proposed is due to the inhibition of keyenzymes involved in the gluconeogenesis and glucogenolysispathway. The same dose showed a marked improvement inGTT of sub and mild diabetic animals by 34.9 and $35.8 \%$ respectively. The present study of severely diabetic animals showed significantlydeclined levels of TC, LDL, and VLDL by 23.4, 24.9 and $50.2 \%$ respectively and enhanced HDL cholesterol level by $28.4 \%$ after two weeks treatment with C. longa. Manyantihypercholesterolemic drugs do not decrease TG levels though TG plays an independent role in increasingly the riskof coronary heart disease $(28,29)$. However, this long-termtreatment of $\mathrm{C}$. longa for two weeks lowered the TG levels tooby $50.3 \%$.Moreover, the enhanced levels of hepatoprotective enzymesdue to severe diabetes such as SGOT, SGPT, ALP and CREwere also reduced by 28.0, 34.6, 34.6, and 8.3\% respectivelyas an additional advantage of this study. TheC. longapowdertogether with milk decreased the glucose concentration in urineby $50 \%$, which is generally high in case of chronic diabeticcases $(30)^{\mathrm{xvii}}$.

\section{Biological properties of Curcumin-cellular and molecular mechanisms of action .}

An experimental study was carried out by B. Joeet al they worked on Curcuminoids, a group of phenolic compounds isolated from the roots of Curcuma longa (Zingiberaceae), exhibit a variety of beneficial effects on health and on events that help in preventing certain diseases. A vast majority of these studies were carried out with curcumin (diferuloyl methane), which is a major curcuminoid. The most detailed studies using curcumin include anti-inflammatory, antioxidant, anticarcinogenic, antiviral, and antiinfectious activities. In 
${ }^{1}$ Dr Kolhe NS , International Journal of Ayurvedic\& Herbal Medicine 7(4) July.-Aug. 2017 (2779-2789)

addition, the wound healing and detoxifying properties of curcumin have also received considerable attention. As a result of extensive research on the therapeutic properties of curcumin, some understanding on the cellular, molecular, and biochemical mechanism of action of curcumin is emerging. These findings are summarized in this review ${ }^{\text {xiii }}$.

(Cissampelous pareira) Berberine lowers blood glucose in type 2 diabetes mellitus patients through increasing insulin receptor expression.

An experimental study was carried out by Zhang, H., et al he says that "Our previous work demonstrated that berberine (BBR) increases insulin receptor (InsR) expression and improves glucose utility both in vitro and in animal models. Here, we study the InsR-up-regulating and glucose-lowering activities of BBR in humans. Our results showed that BBR increased InsR messenger RNA and protein expression in a variety of human cell lines, including CEM, HCT-116, SW1990, HT1080, 293T, and hepatitis B virus-transfected human liver cells. Accordingly, insulin-stimulated phosphorylations of InsR beta-subunit and Akt were increased after BBR treatment in cultured cells. In the clinical study, BBR significantly lowered fasting blood glucose (FBG), hemoglobin A(1c), triglyceride, and insulin levels in patients with type 2 diabetes mellitus (T2DM). The FBG- and hemoglobin A(1c)-lowering efficacies of BBR were similar to those of metformin and rosiglitazone. In the BBR-treated patients, the percentages of peripheral blood lymphocytes that express InsR were significantly elevated after therapy. Berberine also lowered FBG effectively in chronic hepatitis B and hepatitis C patients with T2DM or impaired fasting glucose. Liver function was improved greatly in these patients by showing reduction of liver enzymes. Our results confirmed the activity of BBR on InsR in humans and its relationship with the glucose-lowering effect. Together with our previous report, we strongly suggest BBR as an ideal medicine for T2DM with a mechanism different from metformin and rosiglitazone." ${ }^{\text {xix }}$

Antidiabetic and Glycogenesis Effects of Different Fractions of Ethanolic Extract of Leaves of Mangifera indica (Linn.) in Normal and Alloxan Induced Diabetic Rats .

An experimental study was carried out by M.S. Hossain et alon the $50 \%$ ethanolic extract of the leaves of MI produced a significant hypoglycemic effect at a dose of $250 \mathrm{mg} / \mathrm{kg}$, both in normal and streptozotocininduced diabetic animals. The stimulation of $\beta$-cells to release insulin was thought to be part of the mechanism of action. The effect of the aqueous extract of the leaves of MI on blood glucose level in normoglycaemic, glucose - induced hyperglycaemic and streptozotocin (STZ)-induced diabetic rats has been assessed. The results indicate that the aqueous extract of the leaves of MI possess hypoglycaemic activity. This action may be due to an intestinal reduction of the absorption of glucose. The leaves of MI used for antidiabetic properties using normoglycaemic, glucose-induced hyperglycaemia and streptozotocin (STZ) induced diabetic mice. The aqueous extract of the leaves of MI possess hypoglycaemic activity.The effect of mango (MI) ingestion on blood glucose levels of normal and diabetic rats has been studied. The results from this research suggest that mango flour can possibly help in the treatment of diabetes. The stem-bark of aqueous extract of MI was used to examine the antiinflammatory, analgesic and antidiabetic properties. The different chemical constituents of the plant, especially the polyphenolics, flavonoids, triterpenoids, mangiferin, and other chemical compounds present in the plant may be involved in the observed antiinflammatory, analgesic, and hypoglycemic effects of the plant's extract. The results of this experimental animal study lend pharmacological credence to the suggested folkloric uses of the plant in the management and control of painful, arthritic and other inflammatory conditions, as well as in the management of adultonset type 2 diabetes mellitus in some rural African communities. Investigations were carried out to evaluate the effect of MI on glucose absorption using a rat intestinal preparation in situ. The ethanol extracts of stembarks reduced glucose absorption gradually during the whole perfusion period in type 2 rats. In glucoseloaded normal rats, mangiferin induces a significant improvement in oral glucose tolerance but without 
${ }^{1}$ Dr Kolhe NS , International Journal of Ayurvedic\& Herbal Medicine 7(4) July.-Aug. 2017 (2779-2789)

alteration of basal plasma glucose levels these studies show that mangiferin (10 and $20 \mathrm{mg} / \mathrm{kg}$, i.p.) exhibits potent antidiabetic, antihyperlipidemic, antiatherogenic and antioxidant properties without causing hypoglycaemia; mangiferin would then offer a greater therapeutic benefit for the management of diabetes mellitus and diabetic complications associated with abnormalities in lipid profiles. It has been reported that long standing hyperglycaemia with diabetes mellitus leads to the formation of advanced glycosylated endproducts which are involved in the generation of ROS, leading to oxidative damage, particularly to heart and kidney.

Experimental induction of diabetes: Group 2-6 animals were allowed to fast for $12 \mathrm{~h}$ were rendered diabetic by injection intraperitoneally a freshly prepared solution of alloxan (110 $\mathrm{mg} \mathrm{kg}^{-1}$ b.wt.) in normal saline after base line glucose estimation was done. The alloxan treated animals were allowed to food over night to overcome drug induced hypoglycemia. After $48 \mathrm{~h}$ blood glucose content was measured by using Bioland G423 test meter (Bioland, Germany) using blood sample from the tail vein of the rats. When the condition of diabetes was established animals with blood glucose levels above $11.1 \mathrm{~m} \mathrm{~mol} \mathrm{~L}^{-1}$ was selected for the study $^{\mathrm{xx}}$.

\section{Antidiabetic and Renoprotective effect of the chlorodorm extract of Terminalia Cahebula retz.seeds in streptozotocin -induced Diabetic Rats .}

An experimental study was carried out by Nalamolu Koteswara Raoet al.On the chloroform extract of $T$. chebula seeds produced significant antidiabetic effect with various doses in streptozotocin-induced diabetic rats in acute study. It produced a dose-dependent reduction in blood glucose with doses of 100, 200 and 300 $\mathrm{mg} / \mathrm{kg}$ compared to control group. In the present study the chloroform extract of the seeds of $T$. chebula was evaluated and the data also confirmed the traditional indications. Our data on the seed extract of $T$. chebula indicated a potent action in short term study and a prolonged duration of antidiabetic action in long term study and this could be due to multiple sites of action possessed by the active principles of T. chebula. The study also revealed that $T$. chebula is more effectively inhibited the incidence of diabetic nephropathy. Diabetic nephropathy is mainly associated with excess urinary albumin excretion, abnormal renal function as represented by an abnormality in serum creatinine. The common progression from microalbuminuria to overt nephropathy has led many to consider microalbuminuria to define early or incipient nephropathy. Renal disease is suspected to be secondary to diabetes in the clinical setting of long-standing diabetes. Clinically, diabetic nephropathy is characterized by a progressive increase in proteinuria and decline in GFR, hypertension, and a high risk of cardiovascular morbidity and mortality. The pathophysiology involves glucose that binds irreversibly to proteins in the kidney and circulation to form advanced glycosylation end products (AGEs). AGEs can form complex crosslinks over years of hyperglycemia and can contribute to renal damage by stimulation of growth and fibrotic factors via receptors for AGEs. Increased glomerular capillary pressure occurs early in diabetes and is associated with hyperfiltration at the glomerulus. The glomerular mesangium expands, initially by cell proliferation and then by cell hypertrophy. Increased mesangial stretch and pressure can stimulate this expansion, as can high glucose levels. Mediators of proliferation and expansion include platelet-derived growth factor and transforming growth factor- $\beta$ (TGF$\beta$ ). TGF- $\beta$ are particularly important in the mediation of expansion and later fibrosis via the stimulation of collagen and fibronectin. Angiotensin-II (AT-II) also contributes to the progression of diabetic nephropathy. AT-II preferentially constricts the efferent arteriole in the glomerulus, leading to higher glomerular capillary pressure. In addition to its hemodynamic effects, AT-II also stimulates renal growth and fibrosis through AT-II type 1 receptors, which secondarily upregulate TGF- $\beta$ and other growth factors. The extract due to its significant hypoglycemic activity may have inhibited the formation of advanced glycosylation end products. However the extract may also have effect on the above stated other mechanisms. ${ }^{\mathrm{xxi}}$. 
${ }^{1}$ Dr Kolhe NS , International Journal of Ayurvedic\& Herbal Medicine 7(4) July.-Aug. 2017 (2779-2789)

\section{Antidiabetic activity of hydro -ethanolic extract of Cyperus rotundusin alloxan induced diabetes in} rats.

The antidiabetic effect of of Cyperus rotundus was evaluated on alloxan induced hyperglycemia in rats. Oral daily administration of $500 \mathrm{mg} / \mathrm{kg}$ of the extract once a day for seven consecutive days, significantly lowered the blood gluco se levels[121] Cyperus rotundus $(2.5 \mathrm{ml} / \mathrm{kg}$, orally of $10 \%$ of the aqueous decoction of tuber parts) significantly decreased fasting serum glucose level in alloxan induced diabetic and normoglycemic rabbits. Hypoglycemic effects was appeared from the first week of the treatment, and tended to be increased with the continuation of the treatment[122]. The preventive role of ethanolic extract of Cyperusrotundusrhizomes (CRRE) was investigated on age associated changes in glucose in young and aged rats. CRRE was given as $(500 \mathrm{mg} / \mathrm{kg}$ bw) orally for 30 days. Age associated increase in serum glucose was observed in aged rats compared to young rats. Administration of CRRE to aged rats prevented the age associated changes in glucose level ${ }^{x x i i}$.

Hypolipidaemic activity of Cyperus rotundusrhizomes was evaluated in high fat diet induced hyperlipidaemic rats $(70,140$ and $280 \mathrm{mg} / \mathrm{kg} \mathrm{bw})$. The results demonstrated statically significant reduction in serum lipid profile. Treatment with different doses of extract exerted statistically significant $(\mathrm{p}<0.05)$ reduction in serum total cholesterol, LDL, TG levels at the end of 15 days of intervention[63]. The preventive role of ethanolic extract of Cyperusrotundusrhizomes(CRRE) was investigated on ageassociated changes in glucose and lipids in young and aged rats. CRRE was given as (500 mg/kg body weight) orally for 30 days. Age associated increase in serum glucose, total cholesterol, triglycerides, LDL cholesterol, VLDL cholesterol and a decrease in HDL cholesterol was observed in aged rats compared to young rats. Administration of CRRE to aged rats prevented the age associated changes in glucose, total cholesterol, triglycerides, LDL cholesterol and VLDL cholesterol. HDL cholesterol level was found to be increased significantly in both young and aged rats after treatment with CRRE[109] $]^{\text {xiii }}$.

\section{Discussion and Conclusion}

Diabetes is a major health problem affecting major populations worldwide. Epidemiological studies and clinical trials strongly support the notion that hyperglycemia is the principal cause of complications. Effective blood glucose control is the key for preventing or reversing diabetic complications and improving quality of life in patients with diabetes. Thus sustained reduction in hyperglycemia will decrease the risk of developing microvascular complications and most likely reduce the risk of macrovascular complications ${ }^{\text {xxiv }}$.

Plants may act on blood glucose through different mechanisms, some of them may have insulin-like substances and some may inhibit insulinase activity.[10-11] Stimulation of?-cells to produce more insulin[12] and others may increase? -cells in the pancreas by activating regeneration of pancreatic cells. $[13]^{\mathrm{xxv}}$

Alpha-glucosidase is an intestinal enzyme which breaks down sucrose into glucose and fructose. Alphaglucosidase inhibitors class delay and reduce the amount of glucose that is ready for absorption by interfering with the break down of the long-chain carbohydrates allowing the pancreas more time to secret einsulin to cover the meal ${ }^{\mathrm{xxvi}}$

The histological studies demonstrated severe changes in the pancreas of STZ induced hyperglycemic rats $[18,19]$, whereas BA fruit aqueous extract treatment shows significant recovery when compared with untreated hyperglycemic rats, this could signify the regeneration of beta cells of islets of Langherhans ${ }^{\text {xxvii }}$.

The insulin receptor (InsR) is a membrane-spanning glycoprotein that is essential for the action of insulin.Binding of insulin to InsR in the liver, muscles, or adiposetissues triggers multiple intracellular pathways that causeglycogen synthesis and glucose uptake increase, as well ashepatic/muscle glucose output reduction. The blood glucoselevel is thus lowered[1,2]. This is one of the majormechanisms ${ }^{\mathrm{xxvii}}$. 
${ }^{1}$ Dr Kolhe NS , International Journal of Ayurvedic\& Herbal Medicine 7(4) July.-Aug. 2017 (2779-2789)

Almost all the 12 components of this formulation shows scientific evidence to have beneficial role against diabetes.The review of the above medicinal plants of Katak Kahdiradi Kashaya indicates experimental evidence of anti hyperglycemic activity. This kashayam has been in wide clinical practice by the Ayurvedic physicians in diabetic like clinical condition having good therapeutic result .Therefore, it is appropriate to suggest that the components herbs of this kashayam acts in a complimentary and/or synergistic mode to pronounce the antihyperglycemic effect of the components in the whole formulation.

Further, Ayurvedic remedies for diabetes are usually mixed formulation, containing blood sugar lowering herbs in combination with immunomodulators, antioxidants and urinary system rejuvenating agents. The rationale behind such formulation is provided by modern research, which documents that immune processes play a predominant role in the destruction of beta cell and that free radicals feature predominantly in the progression of the disease and its secondary complication. The inclusion of immunomodulators and detoxifying antioxidants is therefore beneficial.

Strictly speaking, "synergy" or "potentiation" means that the effect of the combination is greater than the sum of the individual effects. One of the best examples of anti-malarial synergy demonstrated both in vitro and in clinical trials is that between atovaquone and proguanil. The activity of the combination is up to eight times greater than that of the individual compounds ${ }^{\text {xix }}$.

Diabetes mellitus is a multi factorial condition, involving multiple pathogenesis and consequently a multipronged approach in management seems more beneficial than a single window approach. Despite the great strides that have been made in the understanding and management of diabetes, the disease and disease related complications are increasing unabated in spite of the presence of known antidiabetic medicine in the pharmaceutical market. Ayurveda offers a significant optimism through its multi-herb formulations used under Ayurvedic Principles to manage this multi-factorial menace challenging the global population.

The attributed antihyperglycemic effects of these plants are due to their ability to restore the function of pancreatic tissues by causing an increase in insulin output or a decrease in the intestinal absorption of glucose. Hence, treatment with herbal drugs has an effect on protecting $\beta$-cells and smoothing out fluctuation in glucose levels. In general, there is very little biological knowledge on the specific modes of action in the treatment of diabetes, but most of the plants have been found to contain substances like glycosides, alkaloids, terpenoids, flavonoids etc. that are frequently implicated as having antidiabetic effects. The research for alternate remedies (from the plant kingdom) for diabetes mellitus will continue all over the world as the disease poses many challenges not only to the physician but also to the researcher.

\section{Reference}

1. Harrisons principles of Internal medicine $16^{\text {th }}$ edition Mc Graw Hills Medical publishing divisionChap 323 pg 2181

2. Attele etal Alternative Medicine Review Feb 2002 7(1) 45-58.

3. Laakso Journal of Internal Medicine, Mar 2001, 249(3) 225-35.

4. Krishnaveni M, Mirunalini S, Karthishwaran K, Dhamodharan G.Anti diabetic and anti hyperlipidemic properties of Phyllanthus embillicaLinn(Euphorbiaceae) on Streptozotocin induced Diabetic Rats Pakistan Journal of Nutrition 2010 9(1) :43-51

5. Harrisons principles of Internal medicine $17^{\text {th }}$ edition McGraw Hills Medical publishing division Chap 338, pg 2296.

6. Semwal BC, Gupta J, Singh S, Kumar Y, Giri M, Antyhyperglycemic activity of root of Berberis Aristata dc in Alloxan induced diabetic Rats.International Journal of Green Pharmacy 2009 3(90): $155-60$ 
${ }^{1}$ Dr Kolhe NS , International Journal of Ayurvedic\& Herbal Medicine 7(4) July.-Aug. 2017 (2779-2789)

7. Raju TP, Shastri KJR, Reddy CS, Reddy VM Anty hyperglycemic activity of stryctunus potatorum seed and Leaf methalonic extract in Alloxan-induced diabetic rats. Research Journal Of Pharmacognosy and Phytochemistry 2010 vol 2(2): 152-154

8. Jarald E, Joshi S B, Jain D C, Biochemical study on the hypoglycemic effects of extract and fraction of Acacia catechu willed in Alloxan induced diabetic rats. Int J Diabetes \& Metabolism 2009 17: 6369

9. Krishnaveni M, Mirunalini S, Karthishwaran K, Dhamodharan G.Anti diabetic and anti hyperlipidemic properties of Phyllanthus embillicaLinn(Euphorbiaceae) on Streptozotocin induced Diabetic Rats Pakistan Journal of Nutrition 2010 9(1) :43-51

10. Suja R.S, Nair AMC, Sujith S, Preethy J, Deepa AK, Evaluation of immunomodulatory potential of Embellica officanalis fruit pulp extract in mice. Indian Journal of Animal Research 2009 43(2): 103 106

11. Jeykodi S, Deshpande J, Juturu V, Salacia extract improves Postprandial glucose and Insulin response: A Randomised double blind placebo controlled crossover study in healthy volunteers. Journal of Diabetes Research 2016 9pages

12. Arul B, Kothai R, Christina AJM,Hypoglycemic activity of Caseria Esculanta Roxb. in normal and diabetic Albino Rats Iranian Journal of Pharmaceutical Research 2006 5(1): 47-51

13. Semwal BC, Gupta J, Singh S, Kumar Y, Giri M, Antyhyperglycemic activity of root of Berberis Aristata dc in Alloxan induced diabetic Rats.International Journal of Green Pharmacy 2009 3(90): 155-60

14. Ananda PK, Kumarappan CT, Christudas S, Kalaichelvan VK Effect of Biophytum sensitivum on Streptozocin and nicotinamide-induced diabetic Rats. Asian Pascific Journal of Tropical Biomedicine Jan 2012 2(1): 31-35

15. Khatib NA, Patil PA, Evaluation of hypoglycemic activity of Barringtonia acutungula fruit exrracts in streptozotocin induced hyperglycemic wistar rats. Journal of Cell and Tissue research 2011 Vol 11(1): 2573-2578

16. Nishiyama T, Male T, Kishinda H, Tsukagawa M, Mimaki Y, Kuroda M et al. Curcuminoids and sesquiterpenoids in Turmeric (Curcuma longa L.) suppress an increase in blood glucose level in type 2 diabetic KK-A ${ }^{\mathrm{y}}$ Mice. Journal of Agricultural and food Chemistry 2005 53(4): 959-963

17. Rai PK, Jaiswal D, Mehta S, Rai DK, Sharma B, Watal G.Effect of curcuma longa freez dried rhizome powder with milk in stz induced diabetic rats. Indian Journal of Clinical Biochemistry Apr 2010 25(2):175-181

18. Joe B, Vijaykumar M, Lokesh BR, Biological properties of curcumin- cellular and molecular mechanism of action. Critical reviews in food science and nutrition 2004 44(2): 97-111

19. Zhang H, Wei J, Xue R, Wu JD, Zhao W, Wang ZZ, etal Berberin lowers blood glucose in type 2 diabetes mellitus patients through increasing insulin receptor expression.Metabolism Clinical and experimental Feb 2010 59(2): 285-292

20. Hossain MS, Khan MRI, Anisuzzaman ASM, Ahmed M, Amran MS, Islam A, antidiabetic and glycogenesis effects of different fractions of ethanolic extract of leaves of Mangifera indica (Linn.) in Normal and Alloxan induced diabetic Rats. Journal of Medical Sciences 2010 10(4): 80-86

21. Rao NK, Nammi S, Antidiabetic and renoprotective effects of the chloroform extract of Terminalia chebula retz. seeds in streptozotocin induced diabetic rats.l Bio Med Central Complementary and Alternative Medicine May 2006 6: 17

22. Raut NA, Gaikwad NJ Antidiabetic activity of hydro ethanolic extract of Cyprus rotundus in alloxan induced diabetes in rats. Fitoterapia 2006 77(7-8): 585-588 
${ }^{1}$ Dr Kolhe NS , International Journal of Ayurvedic\& Herbal Medicine 7(4) July.-Aug. 2017 (2779-2789)

23. Al-Snafi AE, Areview onCyperus rotundus A potential medicinal plant. IOSR Journal of Pharmacy july 2016 6(7): 32-48

24. Jarald E, Joshi S B, Jain D C, Biochemical study on the hypoglycemic effects of extract and fraction of Acacia catechu willed in Alloxan induced diabetic rats. Int J Diabetes \& Metabolism 2009 17: 63 69

25. Semwal BC, Gupta J, Singh S, Kumar Y, Giri M, Antyhyperglycemic activity of root of Berberis Aristata dc in Alloxan induced diabetic Rats.International Journal of Green Pharmacy 2009 3(90): $155-60$

26. Jeykodi S, Deshpande J, Juturu V, Salacia extract improves Postprandial glucose and Insulin response: A Randomised double blind placebo controlled crossover study in healthy volunteers. Journal of Diabetes Research 2016 9pages

27. Khatib NA, Patil PA, Evaluation of hypoglycemic activity of Barringtonia acutungula fruit exrracts in streptozotocin induced hyperglycemic wistar rats. Journal of Cell and Tissue research 2011 Vol 11(1): 2573-2578

28. Zhang H, Wei J, Xue R, Wu JD, Zhao W, Wang ZZ, et al Berberin lowers blood glucose in type 2 diabetes mellitus patients through increasing insulin receptor expression.Metabolism Clinical and experimental Feb 2010 59(2): 285-292

29. Rasioanaivo P. Wright CW Willcox ML Gilbert B, Whole plant extract versus single compound for the treatment of Malaria: Synergy and positive interactions.Malaria Journal 2011 Vol 10(1) S1-S4. 